\title{
Long-Term Compliance With Nonpharmacologic Treatment of Patients With Heart Failure
}

\author{
Maurice M W Nieuwenhuis, Tiny Jaarsma, Dirk J van Veldhuisen, \\ Douwe Postmus and Martje H L van der Wal
}

\section{Linköping University Post Print}

N.B.: When citing this work, cite the original article.

Original Publication:

Maurice M W Nieuwenhuis, Tiny Jaarsma, Dirk J van Veldhuisen, Douwe Postmus and Martje H L van der Wal, Long-Term Compliance With Nonpharmacologic Treatment of Patients With Heart Failure, 2012, American Journal of Cardiology, (110), 3, 392-397. http://dx.doi.org/10.1016/j.amjcard.2012.03.039

Copyright: Elsevier http://www.elsevier.com/

Postprint available at: Linköping University Electronic Press http://urn.kb.se/resolve?urn=urn:nbn:se:liu:diva-82071 
Running head: Long-Term Compliance in Heart Failure

Long-Term Compliance with Non-Pharmacological Treatment of Patients with Heart Failure

Maurice M.W. Nieuwenhuis, MSc ${ }^{\text {a }}$; Tiny Jaarsma, RN PhD ${ }^{\text {a, b }}$; Dirk J. van Veldhuisen, MD $\mathrm{PhD}^{\mathrm{a}}$; Douwe Postmus, $\mathrm{PhD}^{\mathrm{c}}$; Martje H.L. van der Wal, RN PhD ${ }^{\mathrm{a}}$.

${ }^{a}$ University of Groningen, University Medical Center Groningen, Department of Cardiology, Groningen, The Netherlands.

${ }^{\mathrm{b}}$ Linköping University, Department of Social and Welfare Studies, Faculty of Health Sciences, Norrköping, Sweden.

${ }^{\mathrm{c}}$ University of Groningen, University Medical Center Groningen, Department of Epidemiology, Groningen, The Netherlands.

\section{Funding:}

This work was financially supported by the Netherlands Heart Foundation, Den Haag, the Netherlands (Grant 2000Z003).

\section{Corresponding author:}

Maurice M.W. Nieuwenhuis; University of Groningen, University Medical Center Groningen, Department of Cardiology, PO Box 30.001, 9700 RB Groningen, the Netherlands, Tel: +31 50 3611523, Fax: +31 503611731, email: m.m.w.nieuwenhuis@ umcg.nl 


\section{Abstract}

The aim of this study was to examine long-term compliance with non-pharmacological treatment of patients with heart failure (HF) and its associated variables. Data of 648 hospitalized HF patients (mean age 69 \pm 12 years; 38\% female; mean left ventricular ejection fraction [LVEF] $33 \pm 14 \%$ ) were analyzed. Compliance was assessed by means of self-report at baseline and 1, 6 , 12, and 18 months after discharge. Patients completed questionnaires on depressive symptoms, HF knowledge, and physical functioning at baseline. Logistic regression analyses were performed to examine independent associations with low long-term compliance. From baseline to 18 months at follow-up, long-term compliance with diet and fluid restriction ranged from 77\%-91\% and $72 \%-89 \%$ respectively. In contrast, compliance with daily weighing (34\%-85\%) and exercise (48\%-64\%) was lower. Patients who were in New York Heart Association [NYHA]-class II were more often noncompliant with fluid restriction (odds ratio [OR] 1.97, 95\% confidence interval [CI] 1.25-3.08). Lower level of knowledge on HF was independently associated with low compliance with fluid restriction (OR $0.78,95 \%$ CI $0.71-0.86)$ and daily weighing (OR 0.86, 95\% CI 0.79-0.94). Educational support improved compliance with these recommendations. Female sex (OR 1.91, 95\% CI 1.26-2.90), LVEF $\geq 40 \%$ (OR 1.55, 95\% CI 1.03-2.34), a history of stroke (OR 3.55, 95\% CI 1.54-8.16), and less physical functioning (OR $0.99,95 \%$ CI 0.98-0.99) were associated with low compliance with exercise. In conclusion, long-term compliance with exercise and daily weighing was lower than long-term compliance with advice on diet and fluid restriction. Although knowledge on HF and being offered educational support positively affected compliance with weighing and fluid restriction, these variables were not related to compliance with exercise. Therefore, new approaches to help HF patients stay physically active are needed.

Key-words: Adherence; Compliance; Heart Failure; Non-Pharmacological Treatment. 
Although it has been well established, most studies on determinants of compliance in patients with heart failure (HF) are cross-sectional, or focus solely on compliance with 1 specific non-pharmacological recommendation. Data on temporal trends in compliance with cardiovascular medication have been reported previously ${ }^{1}$, but little is known about long-term compliance with non-pharmacological treatment (i.e., sodium-restricted diet, fluid restriction, daily weighing, and exercise) and its determinants. Noncompliance with non-pharmacological treatment is related to adverse outcomes ${ }^{2}$ and lower quality of life. ${ }^{3}$ It is therefore vital to identify those patients who are at risk for noncompliance over a longer period of time, especially since studies have shown that noncompliance is a problem in the HF population. ${ }^{4}$ It has been suggested that compliance with a specific recommendation might be a marker for compliance with other recommendations or lifestyle changes. ${ }^{5}$ Unfortunately, direct comparisons of compliance with different recommendations in the same study population are not available. The present study aims to address this gap by examining long-term compliance with nonpharmacological recommendations and by assessing variables associated with long-term compliance.

\section{Methods}

The study employed a descriptive, prospective design and used data from the $\mathrm{COACH}$ (Coordinating study evaluating Outcomes of Advising and Counseling in Heart failure) study. $\mathrm{COACH}$ was a randomized, multi-center, controlled study in which $1023 \mathrm{HF}$ patients were included between November 2002 and February 2005. ${ }^{6,7}$ Inclusion criteria were an admission for $\mathrm{HF}$, evidence of a structural underlying heart disease, and $\geq 18$ years of age. Exclusion 
criteria were participation in another study, a planned or recent invasive cardiac intervention, or inability to complete questionnaires. $\mathrm{COACH}$ was designed to evaluate the effect of education and counseling by an HF nurse on clinical outcomes in HF patients. Patients were randomized to either a control group ('care as usual', with routine management by a cardiologist) or to 1 of the intervention groups ('basic support' or 'intensive support'). Along with routine management by a cardiologist, patients in both intervention groups received additional care from a HF nurse. This additional care was provided both during hospitalization and after discharge according to protocol and consisted of comprehensive education and counseling about $\mathrm{HF}$ and the $\mathrm{HF}$ regimen. Patients in the intensive group had more contact moments with the HF nurse, including 1 or more home visits. Multidisciplinary advice was also part of the intensive intervention.

The study complied with the Declaration of Helsinki and the Medical Ethics Committee granted approval for the protocol. All patients provided written informed consent and were enrolled and examined during a fixed period of 18 months after discharge from the hospital. Assessments, conducted by an independent data-collector, took place at index hospitalization (baseline) and 1, 6, 12 and 18 months after discharge (follow-up) at the patients' home. Patients completed questionnaires on compliance, HF knowledge, and quality of life. The presence of depressive symptoms was assessed at baseline and 12 and 18 months after discharge. When patients were not able to complete the questionnaires by themselves, the data collector guided the patients through the questionnaires by reading them the questionnaires. At baseline, clinical variables were retrieved from the patients' medical records and by means of structured interviews. Data on left ventricular function were obtained by standard trans- thoracic echocardiography. Patients were included in this study on long-term compliance when they completed the compliance questionnaire during at least 4 out of 5 assessment moments. Only one missing value on each separate recommendation was permitted. When patients had 1 missing value on a specific recommendation during the total follow-up period, this missing 
value was substituted by the lowest compliance score for that specific recommendation on all other assessments.

The Center for Epidemiological Studies Depression scale (CES-D) was used to measure the presence of depressive symptoms. ${ }^{8}$ This scale consists of 20 items and measures the presence of depressive feelings and behaviors. A score of $\geq 16$ indicates the presence of depressive symptoms. To differentiate between patients with moderate or severe depressive symptoms, the following cut-off scores of the CES-D were used: 0-15 (no depressive symptoms), 16-23 (moderate depressive symptoms), and $\geq 24$ (severe depressive symptoms). ${ }^{9}$

Compliance with recommendations on a sodium-restricted diet, fluid restriction, exercise, and daily weighing was measured using the Revised Heart Failure Compliance Scale. ${ }^{10}$ Compliance was measured on a 5-point scale $(0=$ never; $1=$ seldom; $2=$ half of the time; $3=$ mostly; 4 = always). Two HF nurses, experienced in the field of compliance, assessed face validity of the Dutch version of the scale. Patients were defined as compliant with diet, fluid restriction, or exercise when they followed the recommendations 'always' or 'mostly' during the previous week. They were compliant with weighing when they weighed 'daily' or 'at least 3 times a week' during the previous month. When a patient reported to be compliant with a specific recommendation, a score of 1 point was assigned. Since compliance was measured at 5 different assessment moments (baseline and 1, 6, 12 and 18 months during follow-up), the compliance score for each recommendation could range from 0 to 5 points. This long-term compliance score was categorized into either low or high, with a score of 3 or less being defined as 'low long-term compliance'. 'High long-term compliance' indicated compliance at 4 or all 5 assessment moments.

HF knowledge was measured with the Dutch HF knowledge Scale, which consists of 15 multiple choice items (range 0-15), with higher score indicating a higher level of HF knowledge. 
This scale is a reliable and valid instrument for measuring knowledge on HF in general, symptom recognition, and the HF regimen. ${ }^{11}$

Perceived health and physical functioning were assessed using the RAND-36, a selfreport questionnaire of the general health status similar to the Medical Outcome Study 36-item General Health Survey. ${ }^{12,13}$ Patients were asked to score their general health on a 5-point scale $(1=$ excellent to $5=$ bad $)$. Next, patients were divided into two groups: patients who perceived their general health as 'good-excellent' and 'fair-bad'. The subscale 'Physical functioning' consists of 10 items on limitations experienced when performing daily physical activities due to health problems. The total score of the subscale ranges from 0 to 100 , with a higher score indicating better functioning.

Descriptive statistics were used to characterize the study population and to examine longterm compliance with the recommendations. For this study, data of the COACH-study were used. Compliance with each recommendation was therefore also described separately for patients in the control group and for patients who were assigned to 1 of the intervention groups. Since examining differences in compliance between both intervention groups was not the main focus of the present study, data were pooled for the 2 intervention groups and compared with the control group. To assess which baseline variables were independently associated with low longterm compliance, logistic regression analyses were performed. Low long-term compliance was used as the dependent variable; an odds ratio $>1$ indicates a higher probability of being low longterm compliant, whereas an odds ratio $<1$ indicates a lower probability of being low long-term compliant. First, univariable regression analyses were performed to explore which baseline variables were individually associated with low long-term compliance. All theoretically relevant variables for which the Wald test of no association with low long-term compliance had a $\mathrm{p}$ value $<0.10$ were subsequently inserted in a multivariable regression model to determine whether these variables were also independently associated with low long-term compliance. This 
procedure was conducted for all 4 recommendations. SPSS 16.0 statistical software (SPSS Inc, Chicago, IL) was used to perform the statistical analyses.

\section{Results}

Of the 1023 patients participating in $\mathrm{COACH}, 648$ were included in this substudy. A total of 375 (1023-648) patients were excluded: 272 patients died during follow-up period of 18 months and 103 patients did not complete the compliance questionnaires on at least 4 assessment moments, or had more than 1 missing value on a specific recommendation. Compared with included patients, excluded patients were significantly older (74 vs. 69 years, p $<0.001)$, more often lived alone ( $44 \%$ vs. $36 \%, p=0.015)$, were more often in New York Heart Association (NYHA)-functional class III-IV at discharge (58\% vs. 44\%, p <0.001), and more often had an ischemic origin of HF ( $48 \%$ vs. $39 \%, p=0.008)$.

The baseline characteristics of the study population are summarized in Table 1 . The mean age of the study population $(n=648)$ was $69 \pm 12$ years, $38 \%$ were female, and $44 \%$ were in NYHA-class III-IV at discharge with a mean LVEF of $33 \pm 14 \%$ (Table 1). The mean length of HF symptoms was $26 \pm 48$ months. Of all patients, $18 \%$ had moderate and $20 \%$ had severe depressive symptoms. In total, $31 \%$ of the patients were in the 'care as usual' group and $69 \%$ were in 1 of the 2 intervention groups.

Compliance with daily weighing (ranging from 34\%-85\% at the 5 assessment moments) and compliance with exercise (range 48\%-64\%) was lower compared with compliance with a sodium-restricted diet (range 77\%-91\%) and fluid restriction (range 72\%-89\%) (Figure 1). Compliance with diet at 1 month after discharge from the index hospitalization increased from 
$77 \%$ to $91 \%$ and remained stable afterwards. A similar trend was found for compliance with fluid restriction. Compliance with daily weighing increased from $34 \%$ to $85 \%$ at 1 month, but decreased over time to $67 \%$ at 18 months. Although compliance with exercise increased at 1 month, it remained at $\sim 60 \%$ during follow up (Figure 1). Compliance was also examined separately for patients in the control group and for patients in the intervention groups. In both groups, percentages of compliance were also lower for daily weighing and exercise when compared with diet and fluid restriction. Compliance with fluid restriction, and, in particular daily weighing, was higher in the intervention groups (Figure 2 and Figure 3).

Subsequently, low long-term compliance (defined as being compliant at $\leq 3$ out of 5 assessment points during baseline and follow-up) with each separate recommendation was examined. Of all patients, $16 \%$ demonstrated low compliance on the long term with a sodiumrestricted diet and $21 \%$ with fluid restriction. In contrast, $41 \%$ and $54 \%$ respectively showed low compliance with daily weighing and exercise. Of all patients who showed low compliance with $\operatorname{diet}(\mathrm{n}=104), 54 \%$ showed low compliance with fluid restriction, $61 \%$ with daily weighing, and $82 \%$ with exercise. These percentages indicate that low compliance with 1 recommendation does not automatically indicate low compliance with other recommendations on the long term. Similar results were found for low long-term compliance with fluid restriction, weighing, and exercise (Table 2).

In a multivariable analysis, being in NYHA class II was independently associated with low compliance with fluid restriction. Having more knowledge about HF and being assigned to basic- or intensive support were inversely associated with low compliance with fluid restriction, and also with low compliance with daily weighing. This indicates that patients with more knowledge or patients who received additional support were more often compliant over a longer period of time. Women and patients with a LVEF of $\geq 40 \%$ were more likely to have low compliance with exercise. In addition, a history of stroke and poor physical functioning due to 
health problems were associated with low long-term compliance with exercise. No significant associations in univariable or in multivariable analyses were found between compliance with a sodium-restricted diet and possible relevant variables (Table 3).

\section{Discussion}

This is the first study to examine long-term compliance with all aspects of nonpharmacological treatment in HF patients. The main finding of this study is that it appears to be more challenging for patients to become and to maintain compliant with daily weighing and exercise than with a sodium-restricted diet and fluid restriction. Providing education and counseling improved compliance with fluid restriction and daily weighing on the long term, but did not improve compliance with exercise.

Low compliance with daily weighing and exercise has also been demonstrated in previous studies. ${ }^{10,14-16}$ In addition, our study showed that long-term compliance with a particular recommendation does not automatically indicate compliance with other recommendations. This suggests that compliance with the different lifestyle recommendations require different skills from patients. Furthermore, different factors were found to be associated with low compliance after examining all 4 separate recommendations. Our data, however, could not identify factors associated with low compliance with a sodium-restricted diet. This is probably caused by the lack of variance in compliance.

Patients with more HF knowledge and patients who received additional support from the HF nurse during follow-up were more likely to comply with daily weighing over a longer period of time. After 1 month of follow-up, compliance with daily weighing increased both in patients 
who received educational support and in patients who received care as usual. However, compliance with weighing remained high during follow-up in the intervention groups, while compliance decreased in the care as usual group. Although knowledge alone does not ensure compliance ${ }^{16}$, it has nevertheless been confirmed as an important determinant of compliance in the HF literature. ${ }^{17-20}$ An explanation for low compliance with weighing could be that many HF patients do not recognize the importance of daily weighing to check for fluid retention. ${ }^{16}$ Also, having a stable weight over a longer period of time is another reason why patients weigh themselves less often. ${ }^{21}$ Our study showed that providing adequate education on the importance of daily weighing is effective on increasing and maintaining compliance.

Patients with more knowledge about HF and patients who received educational support during follow-up were also more likely to comply with fluid restriction on the long term. In contrast, patients in NYHA class II more often had low long-term compliance with fluid restriction when compared with patients in NYHA class III-IV. A possible explanation for this difference could be that patients in a lower NYHA class are less motivated to comply with the recommendations on fluid intake because they do not experience many of the symptoms associated with HF.

Besides low compliance with daily weighing, we also confirmed low long-term compliance with recommendations on exercise. ${ }^{22}$ Compliance with exercise also influenced the results of the HF-ACTION trial. Patients who fully complied with the exercise intervention had better outcomes, but only $30 \%$ of the patients actually did. Consequently, low compliance with the training regimen may have led to a demise in detecting a significant effect of exercise training on primary outcomes. ${ }^{22}$ Our study showed that less physical functioning and a history of stroke, resulting in physical impairment, were independently associated with low long-term compliance with exercise. Additionally, older patients tended to be more often noncompliant, which suggests that older patients may have less energy or experience more physical symptoms, 
which in turn might affect their ability to comply. ${ }^{10,20} \mathrm{HF}$ symptoms and NYHA class were not associated with compliance with exercise. This indicates that physical symptoms and limitations related to factors such as older age and comorbidity possibly play a larger role in noncompliance with exercise than physical limitations related to HF itself. Health care providers should take these possible physical limitations into consideration, and should try to tailor recommendations on exercise to the specific needs of individual patients.

In contrast with compliance with daily weighing, which improved in patients who received education and counseling according to the $\mathrm{COACH}$-study intervention, this intervention was not effective in increasing compliance with exercise. This suggests that other interventions are needed to improve compliance on the long term. Although it is known that motivational strategies, such as setting goals, giving feedback and solving problems might be effective in the short term, further research is needed to formulate strategies in order to sustain physical activity in HF patients. ${ }^{23}$

Our study has some limitations. Firstly, we used an arbitrary cut-off score to differentiate between patients with low and high long-term compliance. Secondly, data were collected by means of self-report, which may be susceptible to social desirability bias. Patients either completed questionnaires by themselves, or the data collector read them the questionnaires, which may have affected responses of the patients. Since it is not known which patients received assistance with completing the questionnaires, possible mode effects could not be assessed. Nevertheless, all data collectors were independent and trained according to protocol. A final limitation concerns the exclusion of patients who died during follow-up or who had more than 1 missing value on compliance data. This may have biased our data on long-term compliance, since mortality or not completing questionnaires might be due to noncompliance with nonpharmacological treatment. 


\section{Acknowledgements:}

This work was financially supported by the Netherlands Heart Foundation as a part of one of their research programs (Grant 2000Z003).

1. Setoguchi S, Choudhry NK, Levin R, Shrank WH, Winkelmayer WC. Temporal trends in adherence to cardiovascular medications in elderly patients after hospitalization for heart Failure. Clin Pharmacol Ther 2010;88:548-554.

2. van der Wal MH, van Veldhuisen DJ, Veeger NJ, Rutten FH, Jaarsma T. Compliance with non-pharmacological recommendations and outcome in heart failure patients. Eur Heart J 2010;31:1486-1493.

3. Tabet JY, Meurin P, Driss AB, Weber H, Renaud N, Grosdemouge A, Beauvais F, Cohen-Solal A. Benefits of exercise training in chronic heart failure. Arch Cardiovasc Dis 2009; 102:721-730.

4. van der Wal MH, Jaarsma T, van Veldhuisen DJ. Non-compliance in patients with heart failure; how can we manage it? Eur J Heart Fail 2005;7:5-17.

5. Granger BB, Swedberg K, Ekman I, Granger CB, Olofsson B, McMurray JJ, Yusuf S, Michelson EL, Pfeffer MA; CHARM investigators. Adherence to candesartan and placebo and outcomes in chronic heart failure in the CHARM programme: double-blind, randomised, controlled clinical trial. Lancet 2005;366:2005-2011.

6. Jaarsma T, van der Wal MH, Hogenhuis J, Lesman I, Luttik ML, Veeger NJ, van Veldhuisen DJ. Design and methodology of the COACH study: a multicenter randomised Coordinating study evaluating Outcomes of Advising and Counselling in Heart failure. Eur J Heart Fail 2004;6:227-233. 
7. Jaarsma T, van der Wal MH, Lesman-Leegte I, Luttik ML, Hogenhuis J, Veeger NJ, Sanderman R, Hoes AW, van Gilst WH, Lok DJ, Dunselman PH, Tijssen JG, Hillege HL, van Veldhuisen DJ. Effect of moderate or intensive disease management program on outcome in patients with heart failure: Coordinating Study Evaluating Outcomes of Advising and Counseling in Heart Failure (COACH). Arch Intern Med 2008;68:316-324.

8. Radloff LS. The CES-D Scale: a self-report depression scale for research in the general population. Appl Psychol Measur 1977;1:385-401.

9. Lesman-Leegte I, van Veldhuisen DJ, Hillege HL, Moser D, Sanderman R, Jaarsma T. Depressive symptoms and outcomes in patients with heart failure: data from the $\mathrm{COACH}$ study. Eur J Heart Fail 2009;11:1202-1207.

10. Evangelista LS, Berg J, Dracup K. Relationship between psychosocial variables and compliance in patients with heart failure. Heart Lung 2001;30:294-301.

11. van der Wal MH, Jaarsma T, Moser DK, van Veldhuisen DJ. Development and testing of the Dutch Heart Failure Knowledge Scale. Eur J Cardiovasc Nurs 2005;4:273-277.

12. VanderZee KL, Sanderman R, Heyink JW, de Haes H. Psychometric qualities of the RAND 36-Item Health Survey 1.0: a multidimensional measure of general health status. Int J Behav Med 1996;3:104-122.

13. Ware JE, Jr., Sherbourne CD. The MOS 36-Item Short-Form Health Survey (SF-36): I. Conceptual framework and item selection. Med Care 1992;30:473-483.

14. Strömberg A, Mårtensson J, Fridlund B, Levin LA, Karlsson JE, Dahlström U. Nurse-led heart failure clinics improve survival and self-care behaviour in patients with heart failure: Results from a prospective, randomised trial Eur Heart J 2003;24:1014-1023. 
15. Artinian NT, Magnan M, Sloan M, Lange MP. Self-care behaviors among patients with heart failure. Heart Lung 2002;31:161-172.

16. Ni H, Nauman D, Burgess D, Wise K, Crispell K, Hershberger RE. Factors influencing knowledge of and adherence to self-care among patients with heart failure. Arch Intern Med 1999;159:1613-1619.

17. Arcand JA, Brazel S, Joliffe C, Choleva M, Berkoff F, Allard JP, Newton GE. Education by a dietitian in patients with heart failure results in improved adherence with a sodiumrestricted diet: a randomized trial. Am Heart J 2005;150:716.

18. Neily JB, Toto KH, Gardner EB, Rame JE, Yancy CW, Sheffield MA, Dries DL, Drazner MH. Potential contributing factors to noncompliance with dietary sodium restriction in patients with heart failure Am Heart J 2002;143:29-33.

19. Kollipara UK, Jaffer O, Amin A, Toto KH, Nelson LL, Schneider R, Markham D, Drazner MH.. Relation of lack of knowledge about dietary sodium to hospital readmission in patients with heart failure. Am J Cardiol 2008;102:1212-1215.

20. van der Wal MH, Jaarsma T, Moser DK, Veeger NJ, van Gilst WH, van Veldhuisen DJ. Compliance in heart failure patients: the importance of knowledge and beliefs. Eur Heart $J$ 2006;27:434-440.

21. van der Wal MH, Jaarsma T, Moser DK, van Gilst WH, van Veldhuisen DJ. Qualitative examination of compliance in heart failure patients in The Netherlands. Heart Lung 2010;39:121-130.

22. O'Connor CM. Whellan DJ, Lee KL, Keteyian SJ, Cooper LS, Ellis SJ, Leifer ES, Kraus WE, Kitzman DW, Blumenthal JA, Rendall DS, Miller NH, Fleg JL, Schulman KA, 
McKelvie RS, Zannad F, Piña IL; HF-ACTION Investigators. Efficacy and safety of exercise training in patients with chronic heart failure: HF-ACTION randomized control trial. JAMA 2009;301:1439-1450.

23. Tierney S, Mamas M, Woods S, Rutter MK, Gibson M, Neyses L, Deaton C. What strategies are effective for exercise adherence in heart failure? A systematic review of controlled studies. Heart Fail Rev 2011; Epub ahead of print. 


\section{Figure Legends}

Figure 1. Long-term compliance with non-pharmacological treatment $(n=648)$.

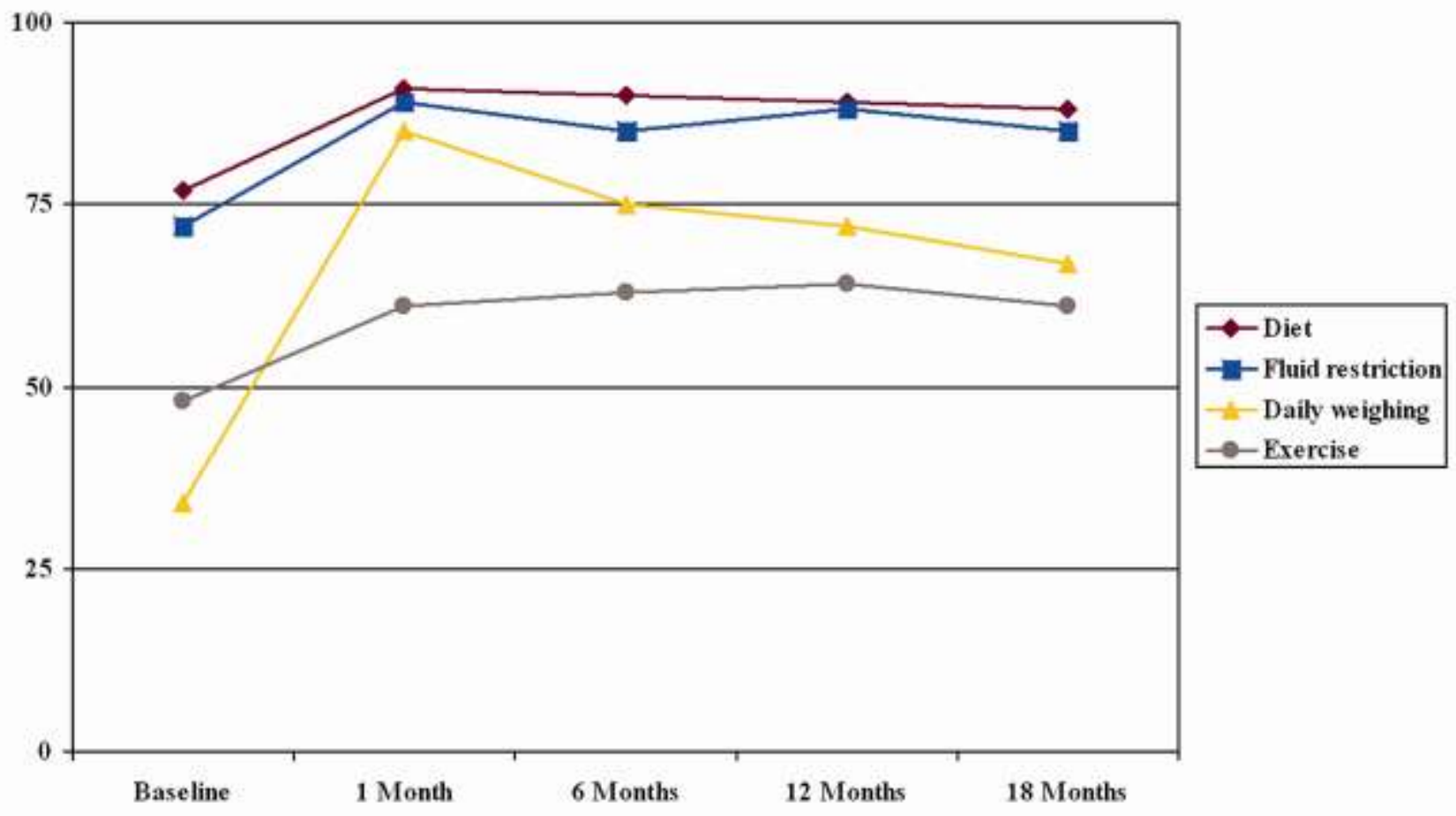


Figure 2. Long-term compliance with a sodium-restricted diet and fluid restriction; 'Care as usual' $(\mathrm{n}=199)$ vs. 'Basic/Intensive support' $(\mathrm{n}=449)$.

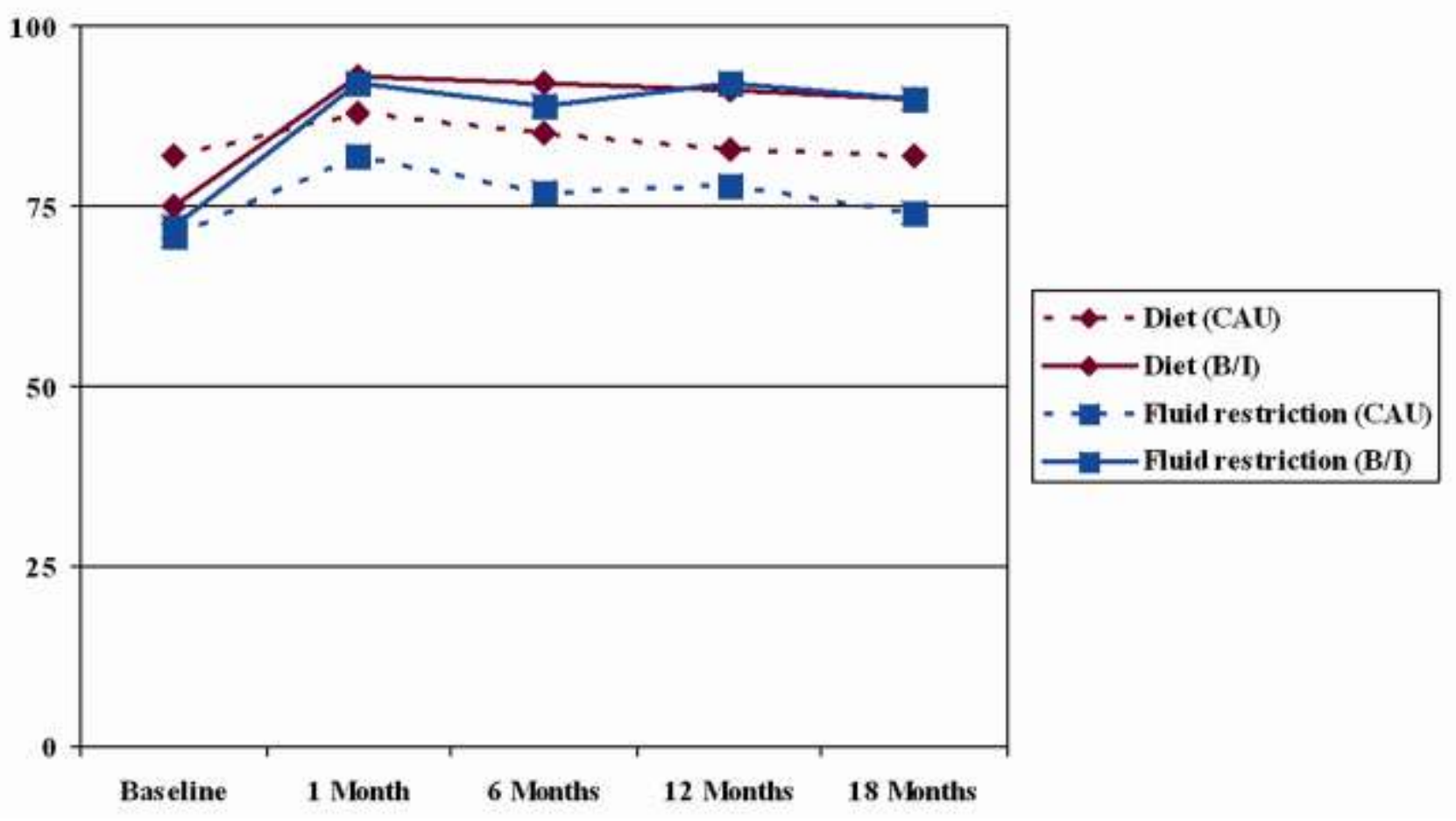

Abbreviations: B/I- Basic/Intensive; CAU- Care as usual. 
Figure 3. Long-term compliance with daily weighing and exercise; 'Care as usual' ( $n=199)$ vs. 'Basic/Intensive support' $(\mathrm{n}=449)$.

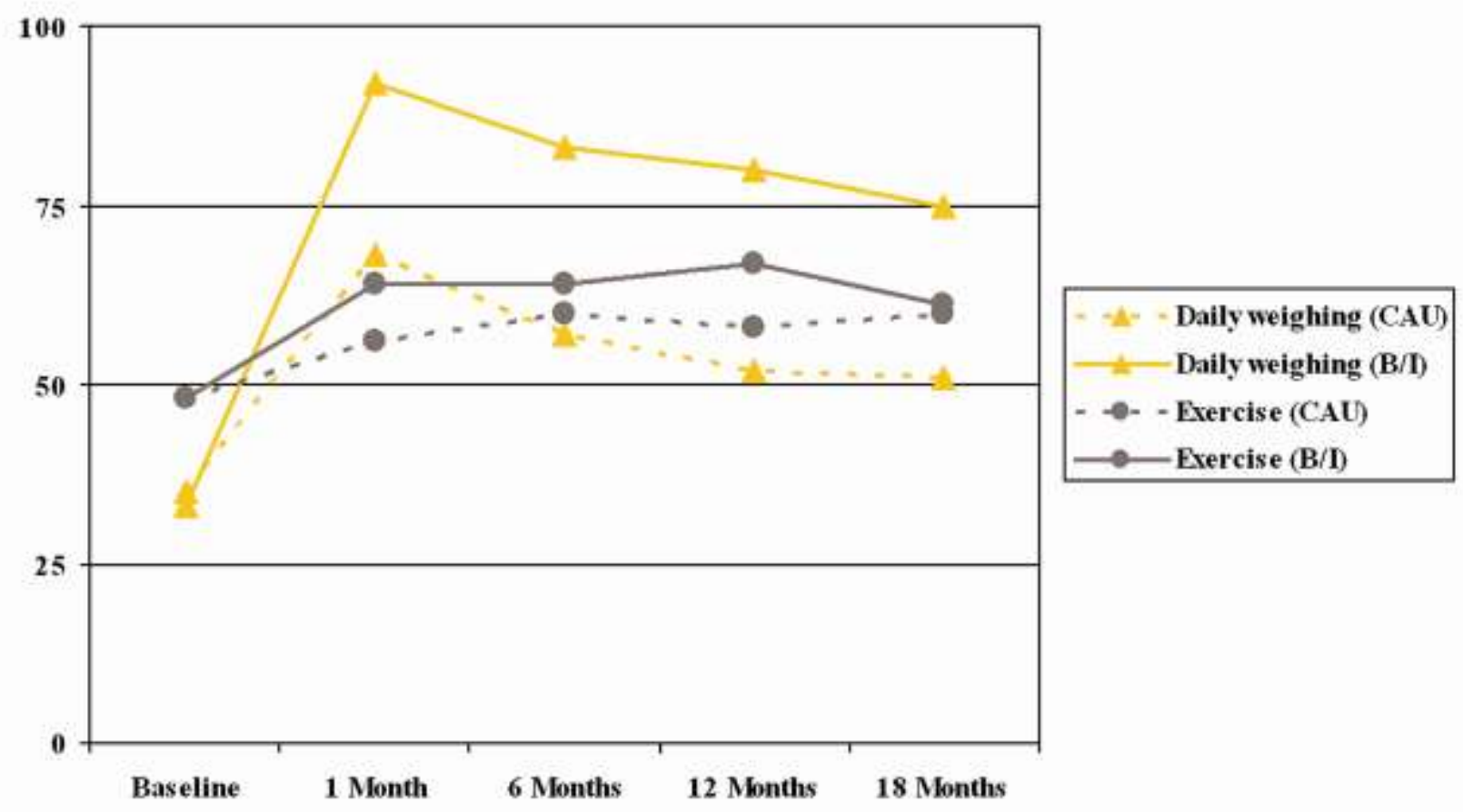

Abbreviations: B/I- Basic/Intensive; CAU- Care as usual. 
Table 1

Baseline characteristics $(n=648)$

Age (years)

Women

Living alone

Educational level (high)

Left ventricular ejection fraction (\%)

Left ventricular ejection fraction $\geq 40 \%$

New York Heart Association-class (III-IV) at discharge

Ischemic origin of heart failure

Length of heart failure (months)

Previous heart failure admission

Depressive symptoms:

Moderate

Severe

Diabetes mellitus

Chronic obstructive pulmonary disease

Stroke

RAND-36

Perceived Health, 'Fair-Bad'

Physical Functioning
$69 \pm 12$

$244(38 \%)$

$233(36 \%)$

$74(11 \%)$

$33 \pm 14 \%$

$187(32 \%)$

$281(44 \%)$

$255(39 \%)$

$26.3 \pm 48.3$

$183(28 \%)$

$112(18 \%)$

$120(20 \%)$

$153(24 \%)$

$160(25 \%)$

$49(8 \%)$

$400(64 \%)$

$39 \pm 27$

Dutch heart failure knowledge scale

Total score

$11.3 \pm 2.3$

Variables are reported as mean \pm SD or number (percentage) 
Table 2

Low long-term compliance with a particular recommendation related to other recommendations

\begin{tabular}{ccccc}
\hline & Diet & Fluid restriction & Daily weighing & Exercise \\
\hline $\begin{array}{c}\text { Diet } \\
(\mathrm{n}=104)\end{array}$ & & $54 \%$ & $61 \%$ & $82 \%$ \\
$(\mathrm{n}=56)$ & $(\mathrm{n}=63)$ & $(\mathrm{n}=85)$ \\
$\begin{array}{c}\text { Fluid restriction } \\
(\mathrm{n}=138)\end{array}$ & $\begin{array}{c}41 \% \\
(\mathrm{n}=56)\end{array}$ & & $65 \%$ & $79 \%$ \\
$\begin{array}{c}\text { Daily weighing } \\
(\mathrm{n}=267)\end{array}$ & $24 \%$ & $(\mathrm{n}=89)$ & $(\mathrm{n}=109)$ \\
& $(\mathrm{n}=63)$ & $(\mathrm{n}=83 \%)$ & & $69 \%$ \\
$\begin{array}{c}\text { Exercise } \\
(\mathrm{n}=352)\end{array}$ & $24 \%$ & $31 \%$ & & \\
\hline
\end{tabular}

This table shows how many patients with low long-term compliance with a specific recommendation also had low compliance with the other recommendations. 
Table 3

Univariable ( $\mathrm{p}$ value $<0.10$ ) and multivariable associations with low long-term compliance

\begin{tabular}{|c|c|c|c|c|c|c|}
\hline Variable & Unadjusted OR $(95 \% \mathrm{CI})$ & $\mathrm{p}$ Value & Adjusted OR $(95 \% \mathrm{CI}) *$ & $\mathrm{p}$ Value & Nagelkerke r square & c-statistic \\
\hline Low compliance, sodium restriction & & & & & 0.019 & 0.582 \\
\hline Chronic obstructive pulmonary disease & $0.59(0.34-1.02)$ & 0.06 & $0.60(0.35-1.03)$ & 0.06 & & \\
\hline Basic/intensive support & $0.66(0.43-1.02)$ & 0.06 & $0.66(0.42-1.03)$ & 0.07 & & \\
\hline Low compliance, fluid restriction & & & & & 0.137 & 0.685 \\
\hline Left ventricular ejection fraction $(\geq 40 \%)$ & $1.54(1.02-2.32)$ & 0.038 & $1.19(0.76-1.86)$ & 0.44 & & \\
\hline New York Heart Association (class II) & $1.68(1.13-2.50)$ & 0.010 & $1.97(1.25-3.08)$ & 0.003 & & \\
\hline Stroke & $2.10(1.13-3.91)$ & 0.019 & $1.57(0.77-3.21)$ & 0.22 & & \\
\hline Heart failure knowledge & $0.77(0.71-0.84)$ & $<0.001$ & $0.78(0.71-0.86)$ & $<0.001$ & & \\
\hline Basic/intervention support & $0.47(0.32-0.69)$ & $<0.001$ & $0.50(0.32-0.77)$ & 0.002 & & \\
\hline Low compliance, daily weighing & & & & & 0.150 & 0.688 \\
\hline Age (years) & $1.03(1.01-1.04)$ & $<0.001$ & $1.01(0.99-1.03)$ & 0.19 & & \\
\hline Living alone & $1.49(1.07-2.06)$ & 0.017 & $1.26(0.86-1.83)$ & 0.24 & & \\
\hline Educational level (high) & $0.61(0.36-1.03)$ & 0.06 & $0.81(0.45-1.44)$ & 0.47 & & \\
\hline Left ventricular ejection fraction $(\geq 40 \%)$ & $1.77(1.25-2.52)$ & 0.001 & $1.44(0.98-2.11)$ & 0.06 & & \\
\hline Heart failure knowledge & $0.85(0.79-0.91)$ & $<0.001$ & $0.86(0.79-0.94)$ & 0.001 & & \\
\hline Basic/intervention support & $0.32(0.23-0.45)$ & $<0.001$ & $0.32(0.21-0.46)$ & $<0.001$ & & \\
\hline Low compliance, exercise & & & & & 0.180 & 0.716 \\
\hline Age (years) & $1.03(1.01-1.04)$ & $<0.001$ & $1.02(0.99-1.04)$ & 0.06 & & \\
\hline Women & $1.83(1.32-2.53)$ & $<0.001$ & $1.91(1.26-2.90)$ & 0.002 & & \\
\hline Living alone & $1.36(0.98-1.88)$ & 0.07 & $0.82(0.54-1.24)$ & 0.34 & & \\
\hline Left ventricular ejection fraction $(\geq 40 \%)$ & $1.57(1.10-2.23)$ & 0.013 & $1.55(1.03-2.34)$ & 0.036 & & \\
\hline New York Heart Association (class II) & $0.63(0.46-0.86)$ & 0.004 & $0.90(0.60-1.35)$ & 0.61 & & \\
\hline Previous heart failure admission & $1.35(0.95-1.90)$ & 0.09 & $1.30(0.83-2.03)$ & 0.25 & & \\
\hline Diabetes Mellitus & $1.41(0.98-2.04)$ & 0.07 & $1.09(0.69-1.73)$ & 0.72 & & \\
\hline Stroke & $3.56(1.75-7.27)$ & $<0.001$ & $3.55(1.54-8.16)$ & 0.003 & & \\
\hline \multicolumn{7}{|l|}{ Depressive symptoms } \\
\hline No symptoms & 1.00 (reference) & & 1.00 (reference) & & & \\
\hline Moderate symptoms & $1.80(1.16-2.77)$ & 0.008 & $1.47(0.88-2.46)$ & 0.14 & & \\
\hline Severe symptoms & $1.73(1.14-2.63)$ & 0.011 & $1.04(0.61-1.75)$ & 0.89 & & \\
\hline Total heart failure symptoms & $1.10(1.02-1.17)$ & 0.010 & $1.01(0.92-1.11)$ & 0.78 & & \\
\hline Perceived health (fair-bad) & $1.93(1.39-2.68)$ & $<0.001$ & $1.28(0.84-1.94)$ & 0.25 & & \\
\hline Physical functioning & $0.98(0.98-0.99)$ & $<0.001$ & $0.99(0.98-0.99)$ & 0.006 & & \\
\hline Heart failure knowledge & $0.86(0.80-0.93)$ & $<0.001$ & $0.93(0.85-1.02)$ & 0.14 & & \\
\hline
\end{tabular}

* Multivariable model includes all variables listed. $\mathrm{CI}=$ confidence interval; $\mathrm{OR}=$ odds ratio 